\title{
The Effectiveness of Polarized Polychromatic Non- Coherent (BIOPTRON) Light in the Management of Acute Lateral Elbow Tendinopathy: A Case Report
}

\author{
Stasinopoulos Dimitrios* \\ Department of Health Sciences, School of Sciences, Cyprus
}

*Corresponding author: Stasinopoulos Dimitrios, Department of Health Sciences, School of Sciences [a] 6, Diogenes Str. Engomi, P.O. Box 22006, 1516, Nicosia, Cyprus

\section{ARTICLE INFO}

Received: 㹃 February 04, 2019

Published: 蔧 February 13, 2019

Citation: Stasinopoulos Dimitrios. The Effectiveness of Polarized Polychromatic Non-Coherent (BIOPTRON) Light in the Management of Acute Lateral Elbow Tendinopathy: A Case Report. Biomed J Sci \& Tech Res 14(3)2019. BJSTR. MS.ID.002562.

Abbreviations: LET: Lateral Elbow Tendinopathy; VAS: Visual Analogue Scale; PRTEE: Patient-Rated Tennis Elbow Evaluation; LLLL: Low Level Laser Light

\section{ABSTRACT}

Background: The effectiveness of the physiotherapy modalities has been investigated in chronic LET. To our knowledge, there have been no studies to find out the effectiveness of physiotherapy modalities in acute LET. The aim of the present report is to find out the effect of polarized polychromatic non-coherent (BIOPTRON) light in acute LET. Case report: A patient with right dominant unilateral LET for less than 48 hours participated in the present case study. The patient followed a course of BIOPTRON light twice per day for five consecutive days. Outcome measures were pain and function, using a visual analogue scale, the Patient-Rated Tennis Elbow Evaluation and the pain-free grip strength. The evaluation of the patient occurred before and after the end of treatment. There was a decline in pain and a rise in function in all evaluations. Conclusion: The results of the present trial suggest that a course of Bioptron light as described in the present trial can produce significant improvements in terms of pain and disability in acute LET.

Keywords: Lateral Elbow Tendinopathy; Bioptron Light; Tennis Elbow; Lateral Epicondylitis; Polarized Polychromatic Non Coherent Light

\section{Introduction}

Lateral elbow tendinopathy (LET) commonly referred to as tennis elbow and / or lateral epicondylitis is the most common tendinopathy in the elbow area. Pain and decreased function are the main symptoms of LET [1]. Diagnosis is simple. The symptoms are reproduced by

a) Gripping activities;

b) Palpation on the site of pain (facet of the lateral epicondyle); and

c) Clinical tests such as resisted middle-finger extension and/ or cozen's test [1].

The management of LET is usually conservative. A plethora of physiotherapy modalities have been recommended for the management of LET. The effectiveness of the recom mended physiotherapy treatments has been investigated in chronic LET. Chronic LET is failed healing tendon response or degenerative rather than inflammatory [2]. To our knowledge, there have been no studies to find out the effectiveness of physiotherapy modalities in acute LET. More recently, physiotherapists can use a new modality called polarized polychromatic non-coherent (BIOPTRON) light. However, the evidence of the Bioptron light in the management of LET, acute or chronic, is minimal. Therefore, the objective of the present report is to find out the effect of Bioptron light in acute LET.

\section{Case Report}

Ms. V., a 23- year-old female complained of acute pain (less than 48 hours) in the lateral aspect of her right elbow, of her dominant hand. The pain was on the facet of the lateral epicondyle. She played tennis for about 4 hours, 36 hours ago. She experienced pain 
about 6 hours after completing the tennis practice. Since then, she complained of constant pain. She was not able to sleep. She did not receive any NSAIDs. She did not have any other symptoms or any problems in peripheral joints or in the spine. In the cozen's test (extension of the wrist with the elbow in extension) the power was 1 on the Oxford scale and there was pain over the facet of the lateral epicondyle of the humerus, 9/10 on the VAS. Resisted extension of the middle finger was painful ( $9 / 10$ on the VAS) on the facet and the power was 1 on the Oxford scale. The reported pain of the patient in the handgrip dynamometer test was $9 / 10$ on the VAS.

All the other movements (passive, active and under resistance movements of the elbow, wrist and neck) were pain free, with full range of motion and strength. Finally, the pain was reproduced by palpation over the common extensor tendon on the facet of the lateral epicondyle of the humerus. The patient received Bioptron light therapy. A Bioptron 2 device administered Bioptron light therapy. Bioptron light therapy was administered to three locations for $6 \mathrm{~min}$ in each location (i.e. $18 \mathrm{~min}$ in total) [3]. The probe of the Bioptron 2 was held at a $900 a n g l e ~ 5-10 \mathrm{~cm}$ above the clean bare skin of the lateral condyle (1) from the upper surface (anterior) with the elbow in extension and the forearm in supination and (2) from the lateral surface with the elbow in 900 of flexion and the forearm in pronation. In addition, the probe of Bioptron 2 was held at a 900angle $5-10 \mathrm{~cm}$ above the clean bare skin of the bellies of the extensor's muscles of the wrist with the elbow in 900 of flexion and the forearm in mid-position of pronation - supination.

The emission of light was administered in 1-min steps and controlled by an integrated soft-start/soft-stop electronic switch. When the treatment with Bioptron 2 was over, there was a characteristic sound (beep tone). Treatment was delivered twice a day (morning and afternoon) for five consecutive days providing ten sessions in total. Function and pain were measured in the present study. The patient was evaluated before and after the treatment period. Pain and function were measured on a visual analogue scale (VAS), a valid and sensitive approach of the LET [4]. In addition, pain-free grip strength was used to measure function as described in previous trial [5]. Finally, pain and function were measured using the Patient-Rated Tennis Elbow Evaluation (PRTEE). The PRTEE questionnaire, provides a very quick (it takes less than 5 min to complete), easy, and standardized quantitative description of pain and functional disability in patients with LET. It has been translated and culturally adapted into Greek [6].

\section{Results}

Pain on VAS was 9, function on VAS was 1, pain-free grip strength was $18 \mathrm{lb}$ and the score of the PRTEE questionnaire was 94 at the initial evaluation. At the end of the treatment (session 10), there was a decline in pain on VAS of 6 units, a rise in function on VAS of 6 units, a rise in pain-free grip strength of 35 units and a decline in the score of the PRTEE questionnaire of 74 units (Table 1).
Table 1: Pain, function, pain-free grip strength and PRTEE questionnaire over the $24 \mathrm{~h}$ before each evaluation.

\begin{tabular}{|c|c|c|c|c|}
\hline Pain (cm) & $\begin{array}{c}\text { Function } \\
\text { (cm) }\end{array}$ & $\begin{array}{c}\text { Pain-Free Grip } \\
\text { Strength (lb) }\end{array}$ & $\begin{array}{c}\text { PRTEE } \\
\text { Questionnaire }\end{array}$ & \\
\hline $\begin{array}{c}\text { Before } \\
\text { Treatment }\end{array}$ & 9 & 1 & 18 & 94 \\
\hline $\begin{array}{c}\text { After } \\
\text { Treatment }\end{array}$ & 3 & 7 & 53 & 20 \\
\hline
\end{tabular}

\section{Discussion}

The present case report has looked at the effect of Bioptron light in a patient experiencing acute LET and its findings have demonstrated significant improvements in terms of pain and disability. The results obtained from this case report are novel; as to date, similar studies have not been conducted. The most common physiotherapy treatment for LET is a supervised or in clinic exercise program [2,7]. However, the patient with acute LET was not able to perform an exercise program due to pain. The patient was advised by the clinician to follow an exercise program after completing the Bioptron light treatment. Like Low Level Laser Light (LLLL), Bioptron light is also a low-power light source but differ from LLLL in that Bioptron light is incoherent and polychromatic rather than coherent and monochromatic [8]. Moreover, Bioptron light combines infrared light at a wavelength of 700-3400nm and visible light at a wavelength of 480-700nm [8]. In contrast, LLLL contains either infrared or visible light at one specific wavelength [8].

Several drawbacks have impaired the usefulness of LLLL in comparison to Bioptron light, such as high risk, required user skills, the small diameter of the laser beam, which allows only a limited area to be treated and high cost [8]. Both the infrared and visible parts of the electromagnetic spectrum of Bioptron light can explain its mechanism of action [8]. It is probable that Bioptron light has biostimulative effects improves the blood supply and accelerates the cellular mechanisms [8], but more research is needed to investigate how this occurs. Since pain relief and improvements in function were noted in the present case study on a short term, it is proposed that Bioptron light may potentially have promoted an anti-inflammatory effect in the soft tissues [8]. However, to understand the potential changes to the tissues in response to Bioptron light therapy, future studies should consider employing outcome assessments that can monitor the changes in deeper tissues. The present case study was the first report to examine the effectiveness of Bioptron light on acute LET.

Previous research assessed the effectiveness of Bioptron light on chronic conditions such as LET $[3,9]$ and carpal tunnel syndrome $[10,11]$. However, acute and chronic conditions are two different conditions and the results are not comparable. In addition, one controlled study assessed the effectiveness of Bioptron light in acute ankle sprains [12], but ankle sprain is a ligament injury whereas LET is a tendon injury. Therefore, ligament injury and ten- 
don injury are two different conditions and the results are not comparable. The previously reported trials found that a course of Bioptron light may improve patients' symptoms. The findings of these trials encourage the design of future well-designed RCTs that might produce strong evidence for the effectiveness of Bioptron light on sports / musculoskeletal injuries. A course of Bioptron light treatment was applied in the present study based on manufacturers claims [13]. It is a dose-response modality and the optimal treatment dose has obviously not yet been discovered.

Future studies are needed to standardize Bioptron light parameters in the management of LET (acute, chronic and calcific) and on other sports / musculoskeletal conditions. Although the positive effects of such a treatment approach in acute LET have been reported in the present study, its study design limits the generalization of these results. Future well-designed trials are needed to confirm the results of this case report establishing the effectiveness of such a treatment approach in the management of LET (acute, chronic and calcific). In addition, structural changes in the tendons related to the treatment interventions are needed to investigate. Further research is needed to establish the cost-effectiveness of such treatment, because reduced cost is an important issue for the recommendation of any given treatment and the possible mechanism of action of this treatment approach [8].

\section{Conclusion}

A course of Bioptron light treatment had reduced the pain and improved the function in a patient with acute LET at the end of the treatment. Further well-designed trials to confirm the results of the present case study are needed.

\section{References}

1. Stasinopoulos D, Johnson MI (2006) Lateral elbow tendinopathy is the most appropriate diagnostic term for the condition commonly referred to as lateral epicondylitis. Medical Hypotheses 67(6): 1399-1401.

2. Coombes BK, Bisset L, Vicenzino B (2015) Management of Lateral Elbow Tendinopathy-One Size Does Not Fit All. J Orthop Sports Phys Ther 45(11): 938-949.

\section{ISSN: 2574-1241}

DOI: 10.26717.BJSTR.2019.14.002562

Stasinopoulos Dimitrios. Biomed J Sci \& Tech Res

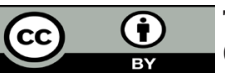

This work is licensed under Creative Commons Attribution 4.0 License

Submission Link: https://biomedres.us/submit-manuscript.php
3. Stasinopoulos D, Stasinopoulos I (2006) Comparison of effects of Cyriax physiotherapy, a supervised exercise programme and polarized polychromatic non-coherent light (Bioptron light) or the treatment of lateral epicondylitis. Clin Rehabil 20(1): 12-23.

4. Stratford P, Levy D, Gauldie S, Levy K, Miseferi D (1987) Extensor carpi radialis tendonitis: a validation of selected outcome measures. Physiother Can 39(4): 250-255.

5. Vicenzino B, Collins D, Wright A (1996) The initials effects of a cervical spine manipulative physiotherapy treatment on the pain and dysfunction of lateral epicondylalgia. Pain 68(1): 69-74.

6. Papadopoulos K, Nardi L, Antoniadou M, Stasinopoulos D (2015) Greek adaptation and validation of the Patient-Rated Tennis Elbow Evaluation (PRTEE) Questionnaire. Journal of Hand Therapy 28(3): 286-291.

7. Bisset LM, Vicenzino B (2015) Physiotherapy management of lateral epicondylalgia. J Physiother 61(4): 174-181.

8. Ioannis M, Michalis T, Dimitrios L, Dimopoulos Christos, Stasinopoulos Dimitrios (2016) Tendinopathy: The Role of Polarised Polychromatic Non-Coherent Light Commonly called Bioptron Light. J Prev Inf Cntrl 2: 2.

9. Stasinopoulos D, Stasinopoulos I, Pantelis M, Stasinopoulou K (2009) Comparing the effects of exercise program and low-level laser therapy with exercise program and polarized polychromatic non-coherent light (bioptron light) on the treatment of lateral elbow tendinopathy. Photomed Laser Surg 27(3): 513-520.

10. Stasinopoulos D, Stasinopoulos I, Johnson MI (2005) Treatment of carpal tunnel syndrome with polarized polychromatic noncoherent light (Bioptron light): A preliminary, prospective, open clinical trial. Photomed Laser Surg 23(2): 225-228.

11. Dimitrios S, Stasinopoulos L (2017) Treatment of Carpal Tunnel Syndrome in pregnancy with Polarized Polychromatic Non-coherent Light (Bioptron Light): A Preliminary, Prospective, Open Clinical Trial. Laser Therapy 26(4): 289-295.

12. Stasinopoulos D, Papadopoulos C, Lamnisos D, Stasinopoulos I (2017) The use of Bioptron light (polarized, polychromatic, non-coherent) therapy for the treatment of acute ankle sprains. Disabil Rehabil 39(5): 450-457.

13. (2002) Visible polarized light information packet Bioptron 2, Harrier Inc. USA.

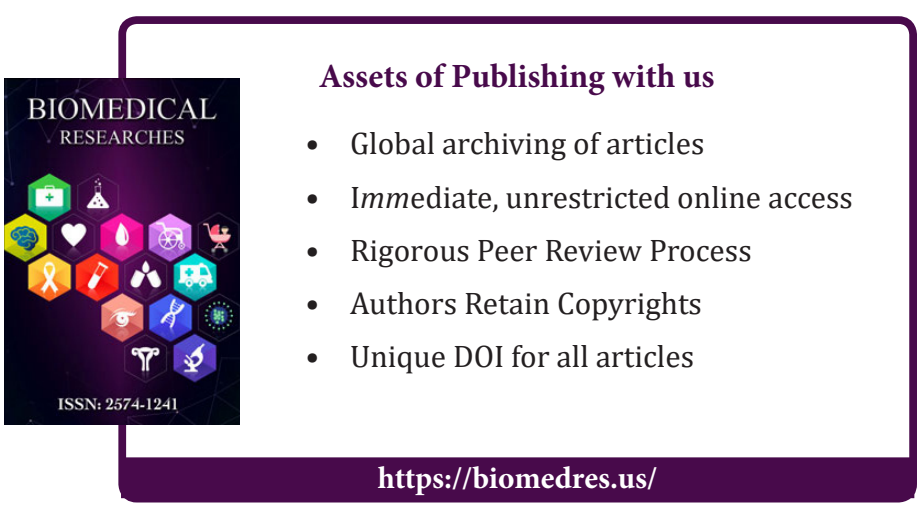

Copyright@ Stasinopoulos Dimitrios| Biomed J Sci \& Tech Res| BJSTR. MS.ID.002562. 